\title{
The Use of the GRAI Method in
}

\section{Re-engineering}

\author{
$R$ MacIntosh $^{l}$ and A S Carrie ${ }^{2}$
}

1. Department of Management Studies, Glasgow University Business

School, 53-59 Southpark Avenue, Glasgow, GI2 8LF, UK

2. DMEM, University of Strathclyde, 75 Montrose Street, Glasgow, GI IXJ, UK

\begin{abstract}
One view of Business Process Re-engineering is that it seeks to do for clerical activities what cellular production systems do for the organisation of manufacturing processes, bringing together all the elements of a process into a single workgroup to provide substantial performance improvements. This paper presents an overview of the GRAI method and its use in a structured approach to re-engineering called the Strathclyde Integration Method. An example of this approach is presented, based on a real re-structuring exercise which was successfully carried out in a manufacturing company. The Strathclyde Integration Method, which involves a combination of Data Flow Diagrams and GRAI Grids, has been used in over ten companies. Based on this experience, the advantages and limitations of GRAI Grids as a re-engineering tool are discussed.
\end{abstract}

GRAI Method, Re-engineering, Integration

\section{Keywords}

\section{INTRODUCTION}

The advocates of Business Process Re-engineering suggest that, as organisations grow or change they become more bureaucratic, their systems become more formalised and many of their business processes are subdivided and distributed among several people in different 
functional departments and locations within the company. By bringing together these elements of a process into a single work group improvements can be achieved. Industrial engineers may take the view that BPR seeks to do for clerical activities what cellular production systems do for the organisation of manufacturing processes. By reorganising business processes, delays and errors in communicating between different groups may be eliminated. The personnel concerned gain a more complete view of the processes and are able to interact with customers in a more knowledgeable way. This creates an environment in which personnel can be made more aware of the organisation's objectives.

Hammer and Champy (1993) state that re-engineering is "the fundamental rethinking and radical redesign of business processes to achieve dramatic improvements in critical, contemporary measures of performance, such as cost, quality, service and speed." The underlying philosophy is to undertake a fundamental review of the objectives of an organisation and the way in which those objectives are currently fulfilled. These objectives are then translated into key processes or functions which must be performed and radical restructuring takes place as the business is re-organised around these key processes. Some have claimed that a universal set of processes can be identified which are common to all manufacturing businesses, but consensus has not been reached on this issue. This reflects a lack of any universally accepted methodology. Some advocate an IT-based approach and seek to develop new software engineering tools. Others adopt a more human work design approach and suggest a methodology similar to TQM. Some argue that BPR has a fundamentally different perspective than TQM in that whereas TQM encourages a regime of incremental continuous improvement, BPR seeks to achieve step-change breakthroughs in performance.

\section{THE GRAI METHOD}

Two fundamental constructs within the GRAI method (Doumeingts, 1989) are the GRAI Grid and the GRAI Net. GRAI Grids provide a diagrammatic overview of the decision making procedures which drive the business. They show the functions of the business and the time scales on which decisions are taken. The major information flows used in decision making processes and the inter-dependency of various decisions can be clearly illustrated. Every decision in a system is mapped onto a matrix according to the function which it performs and the time period for which the decision is relevant. Each location on the matrix is called a decision centre. Each of the decision centres on the grid is then described in greater detail using a GRAI Net. These nets give a more detailed view of how the decision is executed. In the methodology described below GRAI Nets were not used. However GRAI Grids, which are a key part of the methodology, were used.

Functions in the GRAI Grid are not departmental functions in the organisational sense. The GRAI Grid focuses on decision making processes as being the key element of an organisation and defines functions in terms of the decisions concerned. If, for example, decisions and processes from one function on the grid are actually performed across several different departments in the current organisational structure, there would appear to be scope for a reengineering exercise to be conducted. 


\subsection{A STRUCTURED APPROACH TO RE-ENGINEERING USING THE GRAI METHOD}

The Strathclyde Integration Method (Carrie and MacIntosh, 1993 and 1994) uses a combination of Data Flow Diagrams and GRAI Grids to study business processes. The method has been described in a workbook (Carrie et al, 1993). DFDs are used to provide a detailed model of the processes concerned, showing the relationships between individual processes and identifying the flows of material and information from one process to another. From these detailed DFDs, an overview DFD is synthesised which groups the detailed processes into a limited number of "core" processes which form the basis for a GRAI Grid.

The first step in the method, described in Figure 1, is a project planning activity. It involves defining the boundary for the study and identifying those personnel who will have to be interviewed. From this list of interviewees it is possible to estimate the overall duration of the study and the key review dates.

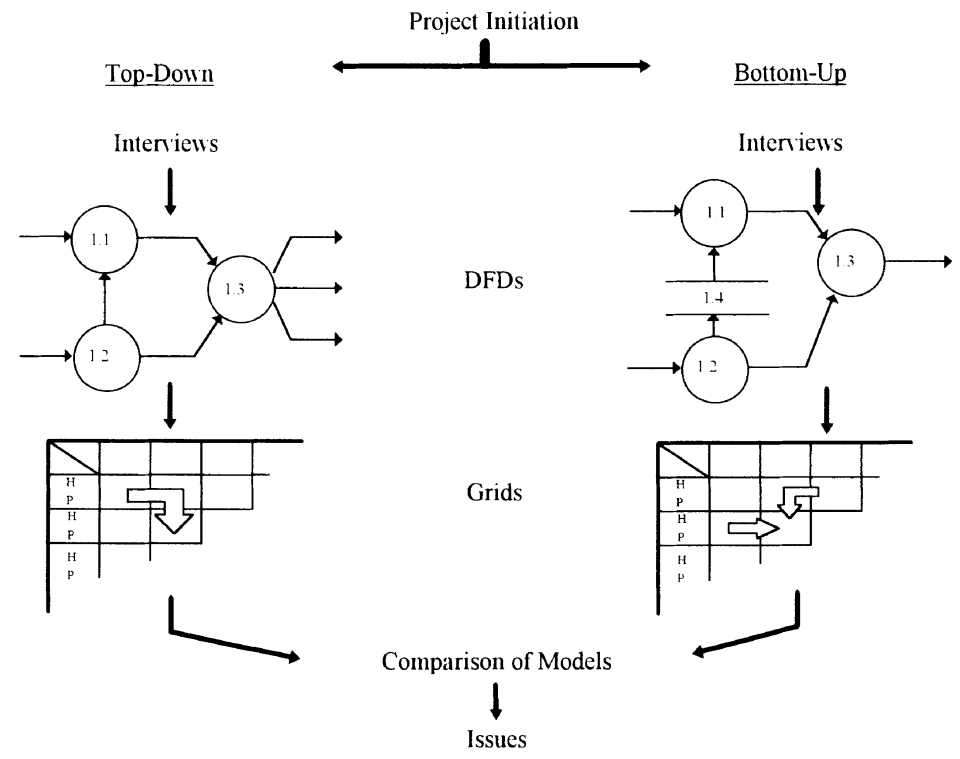

Figure 1 : The steps in the Strathclyde Integration Method.

Having identified the interviewees, two parallel interview sessions begin. This allows a comparison of the relationship between material and information flow from two distinct perspectives to be made. The first set of models, from a top-down perspective, reflect the management's understanding of the organisation regarding material flow, information flow and the decision-making procedures currently in use. The second set of models, from a bottom-up 
perspective, represent the views of those directly involved in daily transfers of material and information and those responsible for taking operational decisions. Typically these are supervisors, operators and clerical staff. This captures both a formal systems viewpoint of the processes and an informal user's viewpoint. These models are constructed independently to ensure that a valid comparison can be made later. Interviews are held with staff from the various departments or functions concerned in each of the business processes. Each interview lasts approximately $30-40$ minutes covering the activities and the information flows through the area as well as any decision making procedures performed. Based on these interviews the DFD models are constructed and then validated by the interviewees.

The method focuses on the decisional processes within the DFD models, since it is these processes that have the greatest impact on the overall performance of the organisation. GRAI Grids are used in order to give an overview of these decision making procedures. All the processes within the DFD models are classified as being either decisional or mechanistic. To identify the decisional processes a list is created of all the processes within the DFD model. Processes which are exploded into greater detail are disregarded, since decisional processes always occur at the lowest level within the model. Those processes which are not exploded any further are classified. The mechanistic processes do not have any decisional content. The decisional processes involve some form of decision and for these it is important to note the time scales involved. Table 1 shows a brief example of the approach used to classify processes. Three possible cases may be encountered, an example is given of each. Process 1.0 is a decisional process but is exploded to a lower level in the DFD model. All processes must only be considered at the lowest level at which they appear in the model. Therefore whether the process is decisional is irrelevant, the time scales of any decisions involved are not applicable until the lowest level of detail is arrived at. Process 1.1 has been exploded to its lowest level of detail but is mechanistic not decisional, time scales are only recorded for the decisional processes. Process 1.2 is a decisional process which is not exploded to another level and therefore the time scales of the decision, in terms of periods and horizons, are noted.

\begin{tabular}{|l|l|c|l|l|}
\hline $\begin{array}{l}\text { Process } \\
\text { Number }\end{array}$ & Description & $\begin{array}{l}\text { Exploded } \\
\text { Yes / No }\end{array}$ & $\begin{array}{l}\text { Decisional } \\
\text { Yes / No }\end{array}$ & Horizon \\
\hline 1.0 & $\begin{array}{l}\text { Schedule } \\
\text { Production }\end{array}$ & Yes & Not Applicable & Not Applicable \\
\hline 1.1 & $\begin{array}{l}\text { Check Technical } \\
\text { Details }\end{array}$ & No & No & Not Applicable \\
\hline 1.2 & Set Priorities & No & Yes & $\mathrm{H}=1$ Week \\
$\mathrm{P}=1$ Day
\end{tabular}

Table 1 - Example of Process Classification 
To create the grid template the columns and rows must be defined. The columns are defined as the functions of the area being studied, e.g. to purchase material, to manage resources etc. These functions are the processes in the overview DFD and the labels from the processes in the overview DFD become the labels for the GRAI Grid columns. The rows of the grid, which represent the time scales of the decisions being made, can be taken from the list of decisional processes, as illustrated by the example given in Table 1 .

With the columns and rows defined, the grid template is complete and individual decisions can be mapped onto the grid. For each decisional process, the function which it relates to can be identified and therefore the column it should be placed under. Also the row on the grid is defined by the periods and horizons found in completing the list of all decisional processes. Once all the decisional processes have been mapped onto the grid, the linkages between them may be added in the form of information flows and decision frames. Having prepared GRAI Grids for each set of DFD models, i.e. top-down and bottom-up it is possible to compare the top-down and bottom-up perspectives. Each grid acts as a summary for the validated DFD model from which it is generated. The DFD models and the grids are explicitly linked by a referencing system so that the analyst can easily move from the summary level grid to the detailed and verified DFD model.

\section{CASE STUDY}

This case study concerns the purchasing function in a company designing and manufacturing complex engineering products, characterised by both deep and wide Bills of Material. The company had suffered a significant reduction in size, caused by a combination of the recession, major cutbacks by their primary domestic customer and the fact that the latest machines were much more powerful than earlier models reducing the number of units required in a market of a given size. The company had existed on the same site throughout its long history but now operated with a substantially reduced workforce. A very hierarchical organisation structure was in place, many of the key processes had been fragmented and spread over a number of departments. This operating environment had remained largely unchanged for some time and the management were ready to consider implementing radical changes. During the process of downsizing the company had reduced its manufacturing capabilities in certain non-core areas and was increasingly reliant on subcontracting work and purchasing bought-in-finished items. The combination of lower staffing levels and increased activity in the purchasing function meant that this department was becoming a problem area. It was decided to use the Strathclyde Integration Method to re-engineer the company's operating practices concerning material supplies.

From initial discussions with the company it was clear that the study would involve three main areas, production scheduling, purchasing and expediting. The purchasing section consisted of buyers and administrators. Customers, suppliers and all other departments within the company and would be considered as external to the study.

Having identified the departments which would be considered in the study, the next task was to obtain a rudimentary understanding of their operation and interaction. Following a brief tour of the departments concerned, a conceptual model was drawn. This simple model did not adhere to any particular modelling conventions and merely provided a sound basis for the more detailed modelling 
which was to follow. With the conceptual model complete, the top-down and bottom-up studies were started as parallel but independent activities.

From these interviews a set of DFDs was constructed for both the top-down and bottom-up perspectives. These initial diagrams were then verified by the interviewees. The top-down model contained 21 diagrams and was 6 levels deep, the bottom-up model contained 16 diagrams and was also 6 levels deep. Both models contained a context diagram showing all of the external entities to the study. The context diagram is then exploded into an overview diagram which contained the main processes involved in the study and their interrelationships in terms of material and information flow. Each of these overview processes is then exploded to show exactly how each activity takes place.

In order to identify the decisional processes within these models, a conversion list was used. This listed all of the processes within each of the DFD models, stating whether each individual process was decisional or not and identifying time scales for those processes which were decisional. A GRAI Grid template was constructed using the processes from the overview diagrams of the DFD models as the functions of the area being studied. These functions were to manage production requirements, to purchase material and to expedite. The time scales identified for individual decisional processes in the conversion lists were used to define the horizons and periods for the grid template.

\begin{tabular}{|c|c|c|c|c|}
\hline $\begin{array}{l}\text { Horizon } \\
\text { Period }\end{array}$ & $\begin{array}{l}\text { Internal } \\
\text { External }\end{array}$ & $\begin{array}{l}\text { To } \\
\text { Manage } \\
\text { Production } \\
\text { Requirements }\end{array}$ & $\begin{array}{l}\text { To } \\
\text { P'urchase } \\
\text { Material }\end{array}$ & $\begin{array}{l}\text { To } \\
\text { Expedite } \\
\text { Material }\end{array}$ \\
\hline $\begin{array}{l}\mathrm{H}=1 \mathrm{~m} \text { th } \\
\mathrm{P}=1 \mathrm{~m} \text { th }\end{array}$ & $\begin{array}{l}\text { Prod'n Depts } \\
\text { Mainframe } \\
\text { Data }\end{array}$ & $\begin{array}{l}\text { Issue Prod'n } \\
\text { Programme } \\
\text { Naintain P'rod'n } \\
\text { Schedule } \\
\end{array}$ & & \\
\hline $\begin{array}{l}\mathrm{H}=2 \mathrm{wks} \\
\mathrm{P}=1 \mathrm{wk}\end{array}$ & $\begin{array}{l}\text { Commercial } \\
\text { Department }\end{array}$ & $\begin{array}{l}\text { Maintain } \\
\text { Contract } \\
\text { BarCharts }\end{array}$ & & \\
\hline $\begin{array}{l}H=1 w k \\
P=1 \text { day }\end{array}$ & & $\begin{array}{l}\text { Issue Minutes of } \\
\text { Prod'n Meting }\end{array}$ & & \\
\hline $\begin{array}{l}\text { Real } \\
\text { Time }\end{array}$ & $\begin{array}{l}\text { Buyer's Action List } \\
\text { (Mainframe) }\end{array}$ & & Issue Orders & $\begin{array}{l}\text { Expedite (Orders } \\
\text { and } \\
\text { Repot Progress }\end{array}$ \\
\hline
\end{tabular}

Figure 2 Simplified top-down GRAI Grid of original situation.

Decisions were then mapped onto the grid template according to the function to which they relate and the frequency with which they occurred. Once all the decisional processes had been mapped 
onto the grid it was possible to link them up using information flows and decision frames. Figures 2 and 3 show simplified GRAI Grids of the original purchasing processes from top-down and bottomup perspectives, respectively. Both grids share the same template, with the same three major functions identified.

When an order was placed for a machine it was registered on the company's mainframe computer, with appropriate details of the Bill of Materials to be used etc. The computer system generated a list of all the items to be purchased for each machine called the Buyer's Action List. The top-down grid, Figure 2, shows mainframe data being used on a monthly basis to maintain the Production Schedule. Another form of the Production Schedule, called the Production Programme, was used on the shop floor by the production departments. A third scheduling device, Contract Bar Charts, were maintained by the Commercial Department and used as the basis for any discussions with customers. Finally, the minutes of the weekly production meeting were issued as the most up-todate set of prioritised orders. The bottom-up grid, Figure 3, omits some of the decision making procedures contained in the top-down view. This is normal, since the bottom-up grid is based on interviews with the operational staff who do not concern themselves with many of the higher level, inter-functional activities described in the top-down grid. The bottom-up grid does, however, show that the expediters receive direct enquiries from production departments looking for specific items which are urgently needed.

\begin{tabular}{|c|c|c|c|c|}
\hline $\begin{array}{l}\text { Forizonction } \\
\text { Period }\end{array}$ & $\begin{array}{l}\text { Internal } \\
\text { External }\end{array}$ & $\begin{array}{l}\text { To } \\
\text { Manage } \\
\text { Production } \\
\text { Requirements }\end{array}$ & $\begin{array}{l}\text { To } \\
\text { Purchase } \\
\text { Material }\end{array}$ & $\begin{array}{l}\text { To } \\
\text { Expedite } \\
\text { Material }\end{array}$ \\
\hline $\begin{array}{l}\mathrm{H}=1 \mathrm{mth} \\
\mathrm{P}=1 \mathrm{mth}\end{array}$ & & $\begin{array}{l}\text { Issue Prod'n } \\
\text { Schedule }\end{array}$ & & \\
\hline $\begin{array}{l}\mathrm{H}=2 \mathrm{wk} \\
\mathrm{P}=1 \mathrm{wk}\end{array}$ & & & & \\
\hline $\begin{array}{l}H=1 \mathrm{wk} \\
\mathrm{P}=1 \mathrm{day}\end{array}$ & & $\begin{array}{l}\text { Issue } M \text { inutes of } \\
\text { Prod'n Meeting }\end{array}$ & & \\
\hline $\begin{array}{l}\text { Real } \\
\text { Time }\end{array}$ & $\begin{array}{l}\text { Buyer's Action List } \\
\text { (Mainframe) } \\
\text { Suppliers }\end{array}$ & & Issue Orders & \\
\hline & & & & \\
\hline
\end{tabular}

Figure 3 Simplified bottom-up GRAI grid of original situation.

Following the application of SIM, a number of issues were identified which were to be addressed in the eventual re-engineering of the purchasing function. Firstly there were several scheduling devices in use. Quite apart from the duplication of effort that this involved, discrepancies inevitably occurred between these documents with the result that departments were working with different priorities. Secondly, the buyers who actually placed the orders had no prioritising mechanism. 
Thirdly, the grids showed a lack of communication between the buyers and the expediter, despite the obvious relationship between the two tasks. Finally, the bottom-up grid showed that the expediters were trying to satisfy conflicting demands from the production departments and the priorities identified in the production schedule (shown by the convergence of two decision frames at one decision centre).

Three major changes were implemented during the re-engineering exercise. Firstly a single production schedule was introduced and all departments within the company worked to this schedule. Secondly, the Buyer's Action List was prioritised using information which was already stored on the mainframe regarding Bill of Material structures and build sequences. Finally the expediting and the purchasing departments were merged. The new purchasing department involved buyers and expediters working in teams to provide a complete purchasing service. These changes are summarised in Figure 4 which shows a simplified GRAI Grid for the re-engineered organisation.

\begin{tabular}{|c|c|c|c|}
\hline $\begin{array}{l}\text { Function } \\
\text { Horizon } \\
\text { Period }\end{array}$ & $\begin{array}{l}\text { Internal/ } \\
\text { External }\end{array}$ & $\begin{array}{l}\text { To } \\
\text { Manage } \\
\text { Production } \\
\text { Requirements }\end{array}$ & $\begin{array}{l}\text { To } \\
\text { Purchase } \\
\text { Material }\end{array}$ \\
\hline $\begin{array}{l}H=1 \mathrm{mth} \\
\mathrm{P}=1 \mathrm{mth}\end{array}$ & Mainframe Data & $\begin{array}{l}\text { Maintain Prod'n } \\
\text { Schedule }\end{array}$ & \\
\hline $\begin{array}{l}H=1 \mathrm{wk} \\
P=1 \mathrm{day}\end{array}$ & Prod'n Depts & $\rightarrow \begin{array}{c}\text { Identify Late } \\
\text { Orders }\end{array}$ & \\
\hline $\begin{array}{l}\text { Real } \\
\text { Time }\end{array}$ & $\begin{array}{l}\text { Prioritised Buyer's } \\
\text { Action List }(\mathrm{M} / \mathrm{F}) \\
\text { Suppliers }\end{array}$ & & $\begin{array}{c}\text { Issue Orders } \\
\text { and } \\
\text { Expedite } \\
1\end{array}$ \\
\hline
\end{tabular}

Figure 4 Simplified GRAI grid of situation after re-engineering exercise

\section{CONCLUSIONS}

An approach to Business Process Re-engineering has been presented based upon the combined use of GRAI grids and Data Flow Diagrams. The Strathclyde Integration Methodology has been applied successfully in over ten organisations. It combines the strengths of structured 
techniques with the overview, insight and flexibility provided by GRAI Grids. The paper demonstrates that SIM can be used as the starting point for a radical re-think of an organisation.

As a result of this experience we offer some comments on the advantages and disadvantages of using GRAI Grids in this BPR methodology.

\subsection{Advantages of GRAI grids}

1 Overview: The GRAI grid however gives a one-page summary of the architecture of a decision-making system, providing an overview in a way no other technique matches.

2 Decision Making Level: By classifying decisions according to period and horizon, the grid sorts decisions according to their place in the decision-making hierarchy. This makes it very easy to distinguish strategic decisions, tactical decisions and operational decisions.

3 Mis-matches With the Organisational Structure: Once constructed, GRAI Grids show the relationship between the organisational structure and the functions which must be performed. If a single organisational department is involved across several functional boundaries then a re-engineering exercise may prove extremely valuable.

\subsection{Limitations of GRAI Grids}

1 Validation of the Existing System: It is necessary to establish and clearly document the existing system. DFDs may be presented to company staff and validated by them as representing a correct understanding of the current system. GRAI Grids on there own do not give sufficient detail for this purpose. Although GRAI Nets could perhaps have been used, they were considered unnecessarily complex for this application.

2 Definitions of Functions: The GRAI method suggests that functions can be classified according to whether they are concerned with managing three key entities, namely products/materials, resources and time, and combinations of them. We found this difficult to apply in practice. Despite this criticism, the underlying concept proved very useful. Flexibility of column definition has proved to be a positive advantage in SIM.

3 The Absence of a Rigorous Methodology: GRAI Grids lack a rigorous support methodology by means of which every analyst would develop the same grid for a given system, or which would allow other analysts to interpret a grid developed by another analyst in the same way.

4 Modelling of Event Driven Situations: GRAI Grids model repetitive, period driven decision making extremely well. However, difficulties can be encountered when using them to model event driven organisations, such as specialist one-of-a-kind manufacturers who tend to use project management type approaches. Many decisions 
only occur in reaction to a particular situation or problem and will not be repeated using a regular period and horizon.

5 Dynamic Modelling of Grids: Exploratory research has been conducted into the dynamic modelling of information systems as represented in GRAI grids. This revealed that several additional related constructs, concerned with time phasing, would be necessary to enable the grid to be unable as a dynamic modelling tool:

- Time required to make a decision

- Delays in communicating between decision centres

- Synchronisation of information flows

- Time phasing of decisions

- Stability.

\section{REFERENCES}

Hammer, M. and Champy, J. (1993) Reengineering the Corporation, Nicholas Breasley Publishing, London.

Doumeingts, G. (1989) GRAI Approach to Designing and Controlling Advanced Manufacturing Systems in a CIM Environment, in Advanced Information Technology for Industrial Material Flow Systems, (eds S Nof and C L Moodie), NATO ASI Series, Volume 53, Springer-Verlag, Berlin, 461-529.

Carrie, A. S., Goldie, A. H., MacIntosh, R., Peoples, G. A. and Warrington, S. W. (1993) The Strathclyde Integration Methodology Workbook, Internal Report, Department of Design, Manufacture and Engineering Management, University of Strathclyde, Glasgow.

Carrie, A. S. and MacIntosh, R. (1993) Improving Integration in Manufacturing Systems, in IFIP Transactions on Advances in Production Management Systems, (eds I A Pappas and I P Tatsiopoulos), North Holland, Amsterdam.

Carrie, A. S. and MacIntosh, R. (1994) A Structured Approach to Process Redesign, Proceedings of the BPICS Annual Technical Conference, Birmingham, 153-167. 


\title{
7. BIOGRAPHY
}

\section{Robert MacIntosh}

Robert MacIntosh is a lecturer in Operations Management with Glasgow University Business School. Previously he was a lecturer in the Department of Design, Manufacture and Engineering Management at the University of Strathclyde where he also worked as a Research Assistant on a three year project investigating Manufacturing Integration with funding from the ACME Directorate of SERC and industrial collaborators. He was involved in developing the Strathclyde Integration Method and has recently completed his $\mathrm{PhD}$ on this subject.

\begin{abstract}
Allan Carrie
Allan Carrie is the Hoover Professor of Advanced Manufacturing Technology at the University of Strathclyde. From 1990 to 1992 he served as Head of the Department of Design, Manufacture and Engineering Management. He is Chartered Engineer, Fellow of the IEE and Member of BPICS. He has industrial experience as an Industrial Engineer with Babcock and Wilcox and with Northern Electric in Montreal, Canada. He is the author of a book on simulation and author of over 80 papers. For the past year he has been a member of the panel on Manufacturing, Production and Business Processes of the Office of Science and Technology's Technology Foresight project.
\end{abstract}

